\title{
A ATUALIZAÇÃO DO VALOR VENAL DOS IMÓVEIS E O AUMENTO DO IPTU: O CASO DE PELOTAS/RS
}

\section{THE UPDATING OF REAL ESTATE VALUES AND THE INCREASE IN IPTU: THE CASE OF PELOTAS/RS}

Guilherme Camargo Massaú

Doutor em Direito pela Universidade do Vale do Rio dos Sinos. Mestre em Direito pela Universidade de Coimbra. Especialista em Ciências Penais Pontifícia Universidade Católica. Professor na Graduação e no Mestrado em Direito da Universidade Federal de Pelotas.

Marcelo Pires Hartwig Graduado em Direito pela Universidade Federal de Pelotas.

Pós-graduado em Direito Tributário pela Pontifícia Universidade Católica do Rio Grande do Sul em parceria com o Instituto de Estudos Tributários.

Resumo: O texto tem como objetivo analisar se a atualização do valor venal dos imóveis na cidade de Pelotas foi justa dentro de parâmetros do cotidiano estável, uma variante da se- gurança jurídica. A atualização do valor venal resultou em aumentos exorbitantes em relação ao valor total do IPTU, em face do exercício do ano de 2014. Tais aumentos atualiza- 
Resumo: O texto tem como objetivo analisar se a atualização do valor venal dos imóveis na cidade de Pelotas foi justa dentro de parâmetros do cotidiano estável, uma variante da segurança jurídica. A atualização do valor venal resultou em aumentos exorbitantes em relação ao valor total do IPTU, em face do exercício do ano de 2014. Tais aumentos atualizadores deveram-se pelo fato da valorização do mercado imobiliário em Pelotas e à inércia de alguns anos sem atualizações no valor venal dos imóveis. O problema que se destaca é a atualização abrupta, pelo poder pú- blico municipal, do valor venal.

Abstract: The text aims to analyze whether the update of the market value of real estate in the city of Pelotas was fair considering daily stable parameters, a variant of legal certainty. The update of the market value resulted in exorbitant increases in the total amount of IPTU, in relation to the financial year 2014. These updates increases were due for the fact that the appreciation of the real estate market in Pelotas and the inertia of a few years without updates on market value of the properties. The pro-

1. Introdução - 2. O direito ao quotidiano estável - 3. IPTU: O caso do Município de Pelotas - 3.1 Aspectos gerais - 3.2 Princípios constitucionais - 4. O caso do Município de Pelotas: o aumento do IPTU - 4.1 Casos concretos do aumento do IPTU pelotense levados ao Poder Judiciário - 4.2 Análise do aumento do IPTU veiculado pela Lei Municipal n. ${ }^{\circ} 6.178 / 14$ sob a ótica constitucional - 5. Conclusão - 6. Notas - 7. Referências bibliográficas

\section{INTRODUÇÃO}

O texto tem como objetivo analisar a abrupta atualização do valor venal dos imóveis no Município de Pelotas, que facultou ao poder público municipal cobrar o Imposto Predial e Territorial Urbano (IPTU) conforme a valorização imobiliária. Porém, tal atualização surpreendeu diversos proprietários de imóveis, já que o aumento, em alguns casos, passou de $1.000 \%$. Des- 
ta forma, o artigo questiona se é admissível que tal diferença de valores se reverifique entre um exercício financeiro e outro, principalmente, quando o contribuinte não tenha liquidamente alterado sua capacidade de contribuição.

Para se percorrer um caminho do geral ao específico, optou-se por iniciar pela concepção do cotidiano estável, que faz parte da ideia de segurança jurídica. Trata-se de uma concepção que defende a função do Direito, além de organizar as interações sociais, também busca estabelecer uma constância na vida social de estabilidade, característica da finalidade do Direito na sociedade.

Passou-se a tratar das características legais do Direito Tributário, especificamente do IPTU, a fim de chamar a atenção que a sua estrutura visa estabelecer a previsibilidade do contribuinte em relação ao poder de tributação do poder público. No entanto, no caso em análise busca-se demonstrar a desestabilização que o poder público pode ocasionar no contribuinte, mesmo agindo dentro dos parâmetros da legalidade. $\mathrm{O}$ aumento excessivo nos valores do imposto pode violar a segurança que o contribuinte espera do Direito, já que a atualização não se deu de forma gradual, devido à inércia do poder público, durante anos.

Por conseguinte, o artigo vai suscitar alguns argumentos estruturais e, após, buscará estabelecer a relação do ordenamento jurídico tributário com os fatos constantes da realidade do município de Pelotas/RS.

\section{O DIREITO AO QUOTIDIANO ESTÁVEL ${ }^{1}$}

A perspectiva adotada nesse texto transcende a concepção de segurança jurídica em sentido amplo (ato jurídico perfeito, coisa julgada e direito adquirido - Art. 5. ${ }^{\circ}, \mathrm{XXXVI}$, da Constituição Federal - CF), que é inerente à ideia de Direito. Isso pelo fato de o Direito necessitar um mínimo de certeza, de eficácia e de ausência de arbitrariedade. Sem essas características não se pode falar em sistema jurídico, menos ainda em Direito Tributário ${ }^{2}$. Nota-se que a segurança jurídica participa na concepção de Direito, também 
se manifestando no ordenamento jurídico como norma, adquirindo contornos mais precisos, principalmente delimitando ideais compositores do sistema jurídico, os objetos que faz referência, os sujeitos protegidos e os contornos com outras normas ${ }^{3}$.

O elemento segurança jurídica faz com que o Direito estabilize as relações intersubjetivas, já que o ser humano não vive só, mas existe por e para os outros, vivendo em sociedade como cocidadão. Nesse sentido ontológico, o Direito exerce uma função de referência na sociedade ${ }^{4}$. Sem tal estabilidade, as relações intersubjetivas descambariam para incertezas e conflitos sociais instransponíveis. Por conseguinte, a ideia de segurança jurídica serve tanto para as relações entre os indivíduos quanto para as relações entre o Estado e os indivíduos.

A concepção de quotidiano estável encontra-se inserido na concepção de segurança jurídica, mas não está materializada numa norma, porém na própria finalidade e sistematicidade do Direito. É justamente a percepção da estabilidade do cotidiano que fornece aos indivíduos as noções de como agir em sociedade sem incorrer em ilícito. Isso ficará exemplarmente evidente no último tópico, quando da análise do caso concreto do IPTU na cidade de Pelotas.

A partir das constituições políticas dos Estados modernos ocidentais, verifica-se que as normas políticas, econômicas, sociais e culturais têm como objetivo a estabilidade da vida das pessoas em suas diversas dimensões. Trata-se de uma estabilidade tácita das normas ${ }^{5}$, principalmente aquelas que dizem respeito entre as relações Estado-indivíduo. Estas relações são baseadas na desproporção de poder entre os polos, logo, distante de ser sinalagmática. Por isso, o princípio da legalidade (Art. 37, caput, da CF) aplicado à Administração Pública possui envergadura distinta em relação ao princípio da legalidade que incide na dimensão privada (Art. 5. ${ }^{\circ}$, II, da CF).

No Direito Tributário, a estabilidade ainda deve ser mais latente, pois envolve os recursos econômicos dos indivíduos, que, em sua grande parte, servem para a subsistência dos mesmos. Por conseguinte, além dos mecanismos de segurança jurídica (princípios) constantes do Direito Tributário, é 
preciso compreendê-lo como um ramo do Direito sensível ao quotidiano dos indivíduos. Entenda-se quotidiano como a rotina diária, o conjunto de fatos vinculados entre si e repetidos e que se realizam com frequência e regularidade $^{6}$.

Dessa forma, o Direito Tributário possui diversos princípios, com força específica, que garantem aos contribuintes segurança e previsibilidade perante os compromissos fiscais que venham a ser constituídos quando da realização do fato gerador. Isso significa que as alterações que ocorrem no Direito Tributário, em termos de oneração do contribuinte, podem ser previstas e confirmadas pelo próprio contribuinte. Nesse sentido, a estrutura jurídica do Direito Tributário é organizada parar manter estável e segura a relação entre contribuinte e fisco, já que este último possui prerrogativas que o deixa em vantagem em relação ao contribuinte em termos de exação fiscal, o que não poderia ser diferente.

Porém, como resguardo do contribuinte, exige-se por parte do Estado de Direito - fisco diversos cuidados, formalidades e condutas condizentes a segurança jurídica e a previsibilidade, para que o contribuinte possa - diante das suas peculiaridades - cumprir com o seu dever sem comprometer sua vida material. Por isso, invoca-se a concepção de estabilidade do cotidiano, que se expressa nas regras e princípios do Direito Tributário. Diga-se que o dever do fisco é observar as regras e princípios, mas também de agir de forma coerente, ou seja, conforme tradicionalmente vem agindo - não contra legem, mas segundo a lei.

Por conseguinte, analisar-se-ão as regras gerais e princípios que incidem no Imposto sobre a Propriedade Predial e Territorial Urbana (IPTU) para que se possa analisar o caso específico do IPTU na cidade de Pelotas.

\section{IPTU: O CASO DO MUNICÍPIO DE PELOTAS}

Cumpre, neste momento, discorrer, em linhas gerais, acerca do Imposto sobre a propriedade predial e territorial urbana (IPTU), apontando, também, pontos relevantes da disciplina específica constante na legislação do Munício de Pelotas. Na sequência, dada a sua importância para o presente estudo, serão abordados os princípios constitucionais aplicáveis ao imposto em estudo. 


\subsection{ASPECTOS GERAIS}

É da competência dos Municípios (Município onde está situado o imóvel $^{7}$ ) instituir imposto sobre "propriedade predial e territorial urbana", tituição esta que deve ser feita por meio de Lei Ordinária Municipal. O Código Tributário Nacional (CTN), nos Arts. 32 a 34, define o fato gerador, base de cálculo e contribuintes do IPTU ${ }^{9}$, estabelecendo o arquétipo possível desses aspectos da norma tributária impositiva, que deverá ser observado pela lei municipal instituidora da exação ${ }^{10}$. No caso de Pelotas, o tributo é atualmente tratado na recente Lei Municipal n. ${ }^{\circ}$ 6.178/2014.

A sujeição passiva do IPTU abrange aquele que detém qualquer direito de gozo relativamente ao bem imóvel, seja pleno ou limitado, conforme se verifica no Art. 34 do $\mathrm{CTN}^{11}$, o qual afirma que o contribuinte do imposto é o proprietário (de domínio exclusivo ou na condição de coproprietário), o titular do domínio útil (enfiteuta e usufrutuário) ou o possuidor (posse ad usucapionem, tão somente) de bem imóvel ${ }^{12}$.

O fato gerador da exação, nos termos do Art. 32 do $\mathrm{CTN}^{13}$, é a "propriedade, o domínio útil ou a posse de bem imóvel, por natureza ou por acessão física, como definido na lei civil, localizado na zona urbana do Município".

Ainda sobre o fato gerador, importante realçar dois aspectos, o espacial e o temporal ${ }^{14}$. Quanto ao espaço (local da ocorrência do fato gerador do IPTU), este é o território urbano do Município ${ }^{15}$. Quanto ao tempo (quando se dá o fato gerador da exação), cumpre afirmar que o imposto é de apuração anual ( $1 .{ }^{\circ}$ de janeiro de cada ano, mediante ficção jurídica $\left.{ }^{16}\right)$.

O IPTU tem o valor venal do imóvel como base de cálculo, consoante o art. 33 do Código Tributário Nacional,_não se considerando o valor dos bens móveis mantidos no imóvel. Considera-se o "valor venal" o preço à vista que o imóvel alcançaria se colocado à venda em condições normais de mercado. Sobre a questão da avaliação do imóvel, importante tecer mais algumas considerações.

O Art. 97, IV, do CTN, dispõe que a base de cálculo dos tributos deve estar prevista em lei, em respeito à estrita legalidade tributária. Apesar disso, ainda que por meio de ato infralegal (v.g., por Decreto Municipal), pode o 
Poder Executivo vir a alterar a base imponível no que se refere à atualização do seu valor monetário, calcado no teor do $\$ 2 .^{\circ}$ do Art. 97 do CTN. Contudo, caso tal ato se exceda em relação aos índices oficiais, veiculando aumento sob a capa de uma "atualização", o excesso será indevido, por violação ao princípio da legalidade tributária ${ }^{17}$.

No caso do Município de Pelotas, a Lei Municipal n. ${ }^{\circ} 6.178 / 2014$, em seu Art. 4. ${ }^{\circ}$, preceitua que o IPTU será calculado sobre o valor venal do imóvel, distinguindo, ainda, para fins de disciplina jurídica, o imposto predial do imposto territorial. Na sequência, dispõe (Art. $5 .^{\circ}$ ) que este valor será determinado com base nos dados cadastrais do imóvel (constantes do Cadastro Imobiliário $^{18}$ ) e corresponderá a soma dos valores do terreno e da edificação, na hipótese de haver edificação sobre o imóvel em questão. Após, apresenta uma série de critérios para a aferição da base de cálculo.

A alíquota do imposto em estudo, naturalmente, avoca a inafastável previsão em lei (Art. 97, IV, do CTN), cuja mitigação se dá apenas no caso dos tributos extrafiscais, grupo ao qual não pertence o IPTU.

A Constituição Federal admite de forma expressa a variação das alíquotas, através da progressividade do IPTU, que deverá estar prevista na lei ordinária municipal, sob pena de afronta ao princípio da legalidade. A Lei Municipal n. ${ }^{\circ}$ 6.718/2014, em seus Arts. 13 e 14, traz alíquotas progressivas, que acompanham o valor venal do imóvel (progressividade fiscal), consoante autoriza o Art. 156, I, da Constituição Federal.

\subsection{PRINCÍPIOS CONSTITUCIONAIS}

Neste momento, em razão da pertinência e relevância ao tema deste trabalho, passa-se a abordar, de forma sintética, os princípios constitucionais que dizem respeito ao IPTU.

O princípio da legalidade ${ }^{19}$ impõe que o tributo só pode ser instituído ou aumentado através de lei (via de regra, como é o caso do IPTU, lei ordinária), não o podendo ser por ato infralegal (v.g., Decreto do Poder Executivo). Todavia, no caso do IPTU, poderá ocorrer a atualização monetária da 
base de cálculo através de norma de caráter infralegal, sem que isso fira a legalidade tributária, eis que tal atualização monetária não configura um aumento efetivo do imposto, mas sim um mero ajuste de valores ${ }^{20}$.

Quanto ao princípio da anterioridade tributária, cumpre afirmar, inicialmente, que este se desdobra no princípio da anterioridade anual e no princípio da anterioridade nonagesimal ${ }^{21}$. Ambos constituem uma vedação temporal ao Poder Público de cobrar tributos, no mesmo exercício financeiro (anterioridade anual) e antes de decorridos noventa dias (anterioridade mitigada) da publicação da lei que instituiu ou aumentou o tributo. Vale lembrar que as vedações são cumulativas. Alguns tributos são exceções às referidas regras, como é o caso do IPTU, imposto que ora se estuda, que não se submete à vedação da anterioridade nonagesimal no que tange à fixação da sua base de cálculo ${ }^{22}$.

Por sua vez, o princípio da isonomia tributária ${ }^{23}$ impede que haja diferenciação tributária entre contribuintes que estejam em situação equivalente. Em outras palavras, veda a discriminação arbitrária.

A diferenciação (não arbitrária ${ }^{24}$ ) permitida pelo ordenamento constitucional se dá em razão de outro princípio, qual seja, o da capacidade contributiva $^{25}$, que guarda íntima relação com o da isonomia. Da capacidade contributiva decorre a ideia de que o Estado deve exigir das pessoas que contribuam para as despesas públicas na medida da sua capacidade econômica, de modo que os mais abastados contribuam mais (progressivamente) em comparação aos menos abastados. Este princípio impõe, também, que a hipótese de incidência elencada por lei diga respeito à situação efetivamente reveladora de riqueza, sob pena de tributação confiscatória.

Importante, também, mencionar o princípio da vedação ao confisco ${ }^{26}$. Entende-se que acontece o confisco quando o Estado absorve a propriedade particular, por meio da tributação, sem justa indenização. Além do direito de propriedade, esta vedação visa proteger os direitos constitucionais da livre iniciativa e do livre exercício profissional. Outrossim, para a verificação do caráter confiscatório de um novo tributo ou majoração, deve-se considerar a carga tributária total a que está submetido o contribuinte, e não apenas analisar cada tributo de forma isolada ${ }^{27}$. 
Ainda dentro do assunto dos princípios constitucionais aplicáveis ao IPTU, cabe mencionar, por sua estreita relação com este assunto, que o IPTU é considerado um imposto real, porquanto considera a propriedade de um imóvel isoladamente e não riquezas que dimensionem a possibilidade atual de o contribuinte pagar tributo (capacidade contributiva). Mesmo assim, a Constituição expressamente autoriza sua progressividade, tanto por razões meramente arrecadatórias ou fiscais como para fins extrafiscais $^{28}$.

\section{O CASO DO MUNICÍPIO DE PELOTAS: O AUMENTO DO IPTU}

Neste momento, será feita uma análise a respeito do aumento do IPTU no Município de Pelotas veiculado pela Lei Municipal n. ${ }^{\circ} 6.178 / 2014$, através da apresentação de dois casos concretos envolvendo a temática levados a juízo, bem como da verificação da conformidade do referido aumento em relação às regras e princípios jurídicos aplicáveis à espécie, incluindo a ideia do direito ao cotidiano estável.

\subsection{CASOS CONCRETOS DO AUMENTO DO IPTU PELOTENSE LE- VADOS AO PODER JUDICIÁRIO}

Cumpre, agora, mencionar os casos concretos que servirão de base para a continuidade do estudo, os quais (entre vários outros que poderiam ser citados) ilustram muito bem os efeitos do aumento do imposto municipal.

As situações apresentadas nos referidos processos podem ser sintetizadas através das tabelas abaixo. A tabela "CASO 1" ilustra caso patrocinado pelo advogado Fabrício Zamprogna Matiello, ao passo que a tabela "CASO 2 " versa sobre demanda patrocinada pelo advogado Matheus Martins Lacerda (ambas na página seguinte).

Feito esse breve resumo, e levando em consideração toda a sólida argumentação utilizada pelos doutos advogados, passa-se, agora, a analisar se as situações apresentadas nos autos de ambos os casos estão em conformidade com o ordenamento jurídico vigente, em especial com os ditames constitucionais. 


\begin{tabular}{|c|c|c|c|}
\hline $\mathrm{CASOL}$ & 2014 & 2015 & Diferenci \\
\hline Valar v'en: & R.848.71।.23 & $\mathrm{R} \$ 641.513 .60$ & R85 $32.802 .37+1.21706)$ \\
\hline Alíquuta & 1.50 & $2 \%$ & $0,5 \%$ \\
\hline IPTU a nagar & RS 7.30.66\% & RS 12.830,2? & RS $12.099,61(1.656 \%$ \\
\hline
\end{tabular}

\begin{tabular}{|c|c|c|c|}
\hline $\mathrm{CASO2}$ & 2014 & 2015 & Diferenca \\
\hline $\begin{array}{l}\text { Valor venal } \\
\text { Alíauota }\end{array}$ & $\begin{array}{c}\mathrm{R} \$ 48.711 .23 \\
1.5 \% \%\end{array}$ & $\begin{array}{c}\text { R. } 641.51 .3 .(1) \\
21 \%\end{array}$ & $\begin{array}{c}\text { RW } 392.802,37(1.2170 \%) \\
0.5 \%\end{array}$ \\
\hline IPTU a pagar & RS 730,66 & RS 12.330 .27 & RS12.(199.61(1.656") \\
\hline
\end{tabular}

\subsection{ANÁLISE DO AUMENTO DO IPTU VEICULADO PELA LEI MU- NICIPAL N. ${ }^{\circ} 6.178 / 14$ SOB A ÓTICA CONSTITUCIONAL}

Partindo de tudo o que foi até aqui exposto, é possível analisar se o aumento do IPTU no Município de Pelotas está de acordo com a ordem jurídico-constitucional vigente, através do cotejo com os princípios jurídicos pertinentes à temática, de forma individualizada.

O princípio da legalidade, tendo em vista que o aumento se deu por meio de lei ordinária, conforme exige a Constituição Federal, foi devidamente respeitado, legitimando a partir dessa dimensão ao aumento do tributo ${ }^{29}$.

Em relação à observância do princípio da anterioridade anual, em termos formais, foi observado, pois a publicação da Lei Municipal n. ${ }^{\circ} 6.718 / 14$ ocorreu em 03 de dezembro de 2014, ou seja, dentro do exercício financeiro anterior ao do aumento. Contudo, é possível argumentar que o princípio da anterioridade foi ferido em sua faceta material, conforme será mais à frente abordado.

No tange ao princípio da anterioridade nonagesimal, verifica-se que este não sofreu violação, eis que o que ocorreu foi um aumento da base de cálculo, que, por se tratar de exceção expressamente prevista na Constituição Federal, não se subordina ao princípio da anterioridade nonagesimal. Em relação à fixação das alíquotas, houve sim desrespeito ao princípio em comento, o que se verifica através da seguinte argumentação ${ }^{30}:$ se a nova legislação houvesse promovido apenas o aumento da base de cálculo dos imóveis (valor venal), a alíquota aplicável, nos termos da legislação anterior, seria de $1,5 \%$ (um e meio por cento) $^{31}$, e não $2 \%$ (dois por cento), como é atual- 
mente cobrado pelo Poder Público Municipal ${ }^{32}$. Desta forma, o referido aumento de alíquota só poderia iniciar-se noventa dias após a publicação da nova lei (início do mês de março de 2015), e, tendo em vista que a lei elege o dia $1{ }^{\circ}$ de janeiro do respectivo exercício financeiro como a data da ocorrência do fato gerador do IPTU, a cobrança do referido aumento só poderia ter início em 2016, sendo inconstitucional fazê-la já no exercício fiscal de 2015;

O princípio da isonomia realizou-se sem máculas, pelo fato de não ter havido diferenciação tributária entre contribuintes em situação equivalente, pois o aumento ocorreu por critérios objetivos.

No que diz respeito ao princípio da capacidade contributiva e ao princípio da vedação ao confisco, a perspectiva é distinta ${ }^{33}$. Um imposto justo deve incidir apenas sobre situação que efetivamente revele manifestação de riqueza por parte do contribuinte, caso contrário, ocorre injustiça fiscal em face do mesmo, podendo haver casos de flagrante restrição ao direito constitucional da propriedade e da livre iniciativa. Considera-se que é o caso do aumento do IPTU pela municipalidade pelotense, pois, em que pese realmente ter ocorrido elevada valorização imobiliária nos últimos anos, há nítida desproporção entre a referida valorização e o aumento do poder aquisitivo dos cidadãos, que, nos casos citados, não foi equivalente ao aumento dos imóveis. Nesse sentido, a elevação da tributação vai muito além da sua manifestação de riqueza, revelando nítido caráter confiscatório. Nesses casos, os proprietários já tinham seus imóveis, e a valorização dos mesmos acarreta um acréscimo - em potência - no patrimônio do proprietário, ou seja, seria preciso que o mesmo vendesse o imóvel por um valor proporcional à valorização imobiliária para que isso fosse traduzido em renda líquida. Ocorre que o imóvel continuou sendo o mesmo, os rendimentos líquidos dos proprietários também permaneceram constantes, logo, uma atualização radical no valor do IPTU é indevida, na medida em que, ao longo dos anos, o mesmo poder municipal permaneceu inerte em relação às atualizações.

Além dos referidos princípios, típicos do Direito Tributário, podem ainda ser referido outros, igualmente importantes, que cabem nos casos concretos em análise. Dessa forma, a razoabilidade ${ }^{34}$, aplicada em matéria tri- 
butária, impõe que as normas devem ser adequadas a realidade dos fatos e que se justifiquem por promoverem de forma efetiva a finalidade colima$\mathrm{da}^{35}$. Nesse sentido, é possível afirmar que o aumento da base de cálculo do IPTU pelotense desrespeita a ideia de razoabilidade no que se refere ao princípio da anterioridade, pois, em que pese, sob o ponto de vista formal, tal princípio ter sido observado, verifica-se que a própria ideia justificadora da anterioridade tributária (não surpresa ${ }^{36}$ ) está sendo inobservada. A partir da razoabilidade, portanto, percebe-se uma afronta ao princípio da anterioridade tributária em seu aspecto material.

Ainda sobre a razoabilidade, cumpre referir que ela, basicamente, estrutura a aplicação de outras normas jurídicas, funcionando, dentre outras acepções possíveis, como uma exigência da harmonização da norma geral com o caso individual, devendo os aspectos peculiares deste caso determinado serem considerados nas hipóteses em que são sobremodo desconsiderados pela generalização da lei. Isso pode ocasionar a não aplicação da norma geral, por configurar um desrespeito a algum princípio constitucional ${ }^{37}$. No tema em estudo, a excessividade do valor e da rapidez do aumento do IPTU no Município de Pelotas fere (pelo menos) os princípios constitucionais da segurança jurídica e da vedação ao confisco, bem como o direito de propriedade, esbarrando, assim, no óbice da irrazoabilidade.

A jurisprudência gaúcha também já se debruçou sobre a temática. Até o momento, encontram-se julgados de agravos de instrumento mantendo decisão liminar proferida em favor do contribuinte, suspendendo o aumento perpetrado pelo ente municipal com base nos princípios de Direito Tributário, especialmente o da capacidade contributiva e o do não confisco, acimatratados ${ }^{38}$.

Feita a análise do aumento do IPTU veiculado pela Lei Municipal $n .^{\circ}$ 6.178/14 em cotejo com os princípios constitucionais tributários, cabe, neste momento, verificar se o direito ao quotidiano estável foi respeitado quando do referido aumento.

O direito ao cotidiano estável (trabalhado em maior abrangência no capítulo 2), que possui intensa relação com o princípio da segurança jurídi$\mathrm{ca}^{39}$, não está materializado em norma jurídica específica, mas sim na per- 
REVISTA DA ESDM - 2016 - V. 2 - N. 04

cepção de que a estabilidade do Direito é fundamental para vida em sociedade, permitindo que os indivíduos tenham segurança na sua rotina diária no que se refere às consequências jurídicas de seus atos. No Direito Tributário, a referida estabilidade é especialmente importante, tendo em vista que envolve o comprometimento dos recursos financeiros dos cidadãos com o Poder Público, numa relação entre desiguais, sendo o Estado, sem qualquer dúvida, a parte mais forte nesta relação. Neste contexto, deve o Direito Tributário servir como uma proteção do indivíduo em face do poder de tributar do Estado, sendo esta, inclusive, a finalidade deste ramo do Direito ${ }^{40}$.

A partir de todas essas ideias, percebe-se que o direito ao cotidiano estável, aliado à razoabilidade, aos princípios da anterioridade nonagesimal (em seu aspecto material), da vedação ao confisco, da segurança jurídica e aos direitos de propriedade e da livre iniciativa, leva ao entendimento de que o aumento da base de cálculo do IPTU efetivado pela Lei Municipal n. ${ }^{\circ}$ 6.178/14 fere o ordenamento constitucional, por, em que pese ter respeitado os aspectos formais, não permitiu que o cidadão pudesse planejar-se adequadamente diante de tão elevado aumento no valor do imposto a pagar, eis que a publicação da nova lei - em 03 de dezembro de 2014 - se deu menos de 1 (um) mês antes da ocorrência do fato gerador, que, por ficção jurídica, acontece em $1 .^{\circ}$ de janeiro do respectivo ano.

\section{CONCLUSÃO}

Ao longo do presente artigo procurou-se estabelecer a hipótese de inadequação de um aumento abrupto no valor do IPTU, mesmo sob a justificativa da atualização do valor venal do imóvel e, ainda, formalmente dentro dos parâmetros legais. Porém, um conjunto de fatores faz suscitar a dúvida da legitimidade material da atualização do valor.

Para tanto, com amparo na doutrina abalizada, foram trazidos os principais aspectos referentes ao imposto em estudo, constitucionais e legais, determinando-se, assim, as bases jurídicas para a análise do aumento ocorrido. 
Após, a fim de ilustrar a questão, trouxeram-se dois casos concretos para a demonstração da irrealidade e da falta da razoabilidade da atualização do valor venal efetuado pelo poder público municipal, o que se verifica através do cotejo com os princípios tributários insculpidos na Constituição, bem como a ideia de cotidiano estável, importante para a plena efetivação da segurança jurídica.

Diante disso, chegou-se a conclusão de que o aumento da base de cálculo do IPTU veiculado pela Lei Municipal n. ${ }^{\circ}$ 6.178/2014 ofende ao ordenamento jurídico-constitucional vigente, especialmente no que se fere aos seguintes princípios e direitos: anterioridade nonagesimal (em seu aspecto material), vedação ao confisco, segurança jurídica (levando em conta também a ideia do cotidiano estável), propriedade, livre iniciativa e razoabilidade.

\section{NOTAS}

1. Concepção ancorada no livro: FONTES, José. O direito ao quotidiano estável. Uma questão de direitos humanos. Coimbra: Coimbra, 2013.

2 .ÁVILA, Humberto. Segurança jurídica. Entre permanência, mudança e realização no Direito Tributário. São Paulo: Malheiros, 2011, p. 127.

3. ÁVILA, Segurança jurídica. Entre permanência, mudança e realização no Direito Tributário. São Paulo: Malheiros, 2011, p. 128.

4. MARQUES, Mário Reis. Introdução ao direito. 2 ed. Coimbra: Almedina, 2007, p. 17 e 21.

5. FONTES, $\mathbf{O}$ direito ao quotidiano estável. Uma questão de direitos humanos. Coimbra: Coimbra, 2013, p. 20-21.

6. FONTES, $\mathbf{O}$ direito ao quotidiano estável. Uma questão de direitos humanos. Coimbra: Coimbra, 2013, p. 34.

7. SABBAG, Eduardo. Manual de direito tributário. 7 ed. São Paulo: Saraiva, 2015, p. 1071.

8. Constituição Federal, artigo 156, inciso I.

9. Consoante a determinação constante no artigo 146, inciso III, alínea "a", da Lei Maior.

10. PAULSEN, Leandro. Curso de direito tributário completo. 6 ed. Porto Alegre: Livraria do Advogado, 2014, p. 237. 
REVISTA DAESDM - 2016 V.2 $-N .04$

11. Dispositivo correspondente no artigo 3. ${ }^{\circ}$ da Lei Municipal n. ${ }^{\circ} 6.178 / 2014$.

12. Não cabe, neste trabalho, abordar a polêmica questão de o CTN ter extrapolado (ou não) os limites constituições ao elencar outros direitos reais, além da propriedade, como sendo fatos geradores do IPTU. Nesse sentido, recomenda-se a leitura de: DUARTE, Francisco Leite. Direito tributário aplicado. São Paulo: Editora Revista dos Tribunais, 2013, p. 613-617

13. Dispositivo correspondente no artigo $1 .^{\circ}$ da Lei Municipal n. ${ }^{\circ} 6.178 / 2014$.

14. SABBAG, Manual de direito tributário. 7 ed. São Paulo: Saraiva, 2015, p. 1084.

15. Artigos 156, I, da CF e 32 do CTN.

16. Artigo 2. ${ }^{\circ}$ da Lei Municipal n. ${ }^{\circ} 6.178 / 2014$.

17. Neste sentido, inclusive, é o Enunciado n. ${ }^{\circ} 160$ da Súmula do Superior Tribunal de Justiça: "É defeso, ao Município, atualizar o IPTU, mediante decreto, em percentual superior ao índice oficial de correção monetária”.

18. Em seu Art. 16, a Lei Municipal n. ${ }^{\circ}$ 6.178/2014 exige que todos os imóveis situados na zona urbana do Município sejam inscritos no Cadastro Imobiliário.

19. Previsto no artigo 150, inciso I, da CF.

20. SABBAG, Manual de direito tributário. 7 ed. São Paulo: Saraiva, 2015, p. 1084-85.

21. Previstos, respectivamente, nas alíneas "b" e "c" do artigo 150, inciso III, da CF.

22. Exceção prevista no artigo $150, \S 1 .^{\circ}$, parte final, da CF.

23. Previsto no artigo 150, inciso II, da CF.

24. As hipóteses de diferenciação que não guardem relação direta com a capacidade contributiva devem encontrar expresso amparo constitucional. No caso do IPTU, por exemplo, a Constituição Federal autoriza a utilização extrafiscal do IPTU para induzir o cumprimento da função social da propriedade (artigo 182, $\$ 4 .^{\circ}$, inciso II, da CF). PAULSEN, Curso de direito tributário completo. 6 ed. Porto Alegre: Livraria do Advogado, 2014, p. 63.

25. Previsto no artigo $145, \$ 1 .^{\circ}$, da CF.

26. Artigo 150, inciso IV, da CF.

27. Leandro Paulsen traz interessante exemplo. Trata-se da ADI 2.010, oportunidade na qual o STF entendeu que o aumento da contribuição previdenciária do servidor público a patamares que poderiam chegar a $25 \%$, associado à incidência do imposto sobre a renda de 27,5\%, implicava confisco, suspendendo, assim, a majoração da contribuição. PAULSEN, Leandro. Curso de direito tributário completo. 6 ed. Porto Alegre: Livraria do Advogado, 2014, p. 107.

28. O artigo $156, \S 1 .^{\circ}$, da CF, autoriza a progressividade do IPTU em razão do valor do imó- 
vel (inciso I), bem como a sua seletividade, de modo que tenha alíquotas diferentes de acordo com a localização e o uso (inciso II). Já o art. 182, que cuida da política de desenvolvimento urbano, faculta ao Município exigir do proprietário de terreno urbano que promova seu adequado aproveitamento, sob pena de parcelamento ou edificação compulsórios, IPTU progressivo no tempo e desapropriação, razão pela qual os proprietários de terrenos urbanos pagam mais IPTU que os proprietários de casas, embora o valor venal dessas com seus terrenos seja muito superior ao daqueles.

29. Ressalta-se que, nos casos apresentados, levantou-se a existência vício formal insanável ocorrido na tramitação do projeto de lei, por desrespeito ao Regimento Interno da Câmara Municipal de Pelotas.

30. Utilizada pelo nobre advogado Matheus Martins Lacerda, no processo de seu patrocínio. Ressalta-se que não a majoração indevida das alíquotas não atinge a toda e qualquer situação, devendo ser analisada casuisticamente.

31. Consoante o artigo 3..$^{\circ}$, inciso III, alínea “c”, da Lei Municipal n. 5.635/09.

32. Consoante o artigo 13, alínea “c”, da Lei Municipal n. ${ }^{\circ} 6.178 / 14$.

33. Em razão da proximidade destes princípios, sua análise será feita de forma conjunta.

34. Preferiu-se não utilizar a comum expressão "princípio da razoabilidade" em razão de que, consoante a doutrina abalizada, a razoabilidade trata-se, em verdade, de uma metanorma, que serve como estrutura de aplicação de outras normas, caracterizando-se como um postulado normativo aplicativo, ou, apenas, postulado. PAULSEN, Curso de direito tributário completo. p. 55-56.

35. PAULSEN, Curso de direito tributário completo. 6 ed. Porto Alegre: Livraria do Advogado, 2014, p. 66.

36. DUARTE, Direito tributário aplicado. São Paulo: Editora Revista dos Tribunais, 2013, p. 238.

37. ÁVILA, Teoria dos Princípios. São Paulo: Malheiros, 2011, p. 102-104.

38. Entre outros, pode ser citado o Agravo de Instrumento n. ${ }^{\circ} 71005703970$ - TJRS.

39. PAULSEN, Curso de direito tributário completo. 6 ed. Porto Alegre: Livraria do Advogado, 2014, p. 61.

40. MACHADO, Curso de direito tributário. . 31 ed. São Paulo: Editora Malheiros, 2010, p. 56. 


\section{REFERÊNCIAS BIBLIOGRÁFICAS}

ÁVILA, Humberto. Segurança jurídica. Entre permanência, mudança e realização no Direito Tributário. São Paulo: Malheiros, 2011.

ÁVILA, Humberto. Teoria dos Princípios. Da definição à aplicação dos princípios jurídicos. 4 ed. São Paulo: Malheiros, 2005.

BRASIL. Constituição Federal de 1988. Promulgada em 5 de outubro de 1988. Disponível em:<http://www.planalto.gov.br/ccivil_03/constituicao/constituição.htm>.

BRASIL. Código Tributário Nacional. Disponível em: <http://www.senado.leg.br/bdsf/ bitstream/handle/id/496301/000958177.pdf? sequence $=1>$.

DUARTE, Francisco Leite. Direito tributário aplicado. São Paulo: Editora Revista dos Tribunais, 2013.

FONTES, José. O direito ao quotidiano estável. Uma questão de direitos humanos. Coimbra: Coimbra, 2013.

MACHADO, Hugo de Brito. Curso de direito tributário. 31 ed. São Paulo: Editora Malheiros, 2010.

MARQUES, Mário Reis. Introdução ao direito. 2 ed. Coimbra: Almedina, 2007.

NETO, Celso de Barros Correia. Caberá ao Supremo definir os limites para o aumento do IPTU. Rede Mundial de Computadores, CONJUR, http://www.conjur.com.br/ 2014-set-13/observatorio-constitucional-cabera-supremo-definir-limites-aumentoiptu, acesso em 28/03/2016.

PAULSEN, Leandro. Curso de direito tributário completo. 6 ed. Porto Alegre: Livraria do Advogado, 2014.

PELOTAS. Lei Municipal n. ${ }^{\circ}$ 6.178/2014, 03 de dezembro de 2014. Disponível em: < http://www.pelotas.rs.gov.br/interesse_legislacao/leis/2014/6178.pdf>.

PELOTAS. Lei Municipal n. ${ }^{\circ}$ 5.635/09, 24 de novembro de 2009. Disponível em: http:// sapl.camarapel.rs.gov.br/sapl_documentos/norma_juridica/337_texto_integral>.

SABBAG, Eduardo. Manual de direito tributário. 7 ed. São Paulo: Saraiva, 2015. 